\title{
Oncogenic Activity of miR-650 in Prostate Cancer Is Mediated by Suppression of CSR1 Expression
}

\author{
Ze-Hua Zuo, ${ }^{*}$ Yan P. Yu,${ }^{*}$ Ying Ding, ${ }^{\dagger}$ Silvia Liu, ${ }^{\dagger}$ Amantha Martin, ${ }^{*}$ George Tseng,${ }^{\dagger}$ and Jian-Hua Luo*
}

From the Departments of Pathology* and Biostatistics, ${ }^{\dagger}$ University of Pittsburgh School of Medicine, Pittsburgh, Pennsylvania

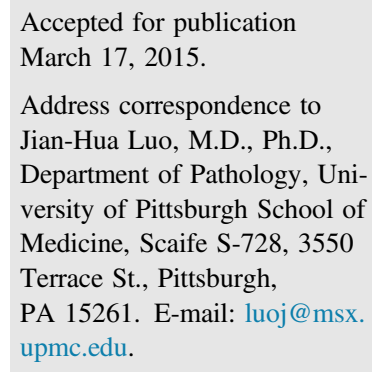

\begin{abstract}
Cellular stress response 1 (CSR1) is a tumor suppressor gene whose expression was frequently down-regulated in prostate cancer. The mechanism of its down-regulation, however, is not clear. Here, we show that the $3^{\prime}$ untranslated region of CSR1 contains a target site of miR-650. High level of miR-650 was found in prostate cancer samples and cell lines. Degradation of miR-650 by specific inhibitor dramatically increased the expression levels of CSR1. Interaction between miR-650 and its target site in the $3^{\prime}$ untranslated region was validated through luciferase reporter system. Mutation at the target site completely abrogated the activity of miR-650 on the $3^{\prime}$ untranslated region of CSR1. Inhibition of miR-650 reversed the expression suppression of CSR1, suppressed colony formation, and blocked cell cycle entry to the S phase of both PC3 and DU145 cells. Animal model showed significant decrease of tumor volume, rate of metastasis, and mortality of severe combined immunodeficient mice xenografted with PC3 or DU145 cells transformed with inhibitor of miR-650. Our analyses demonstrate that suppression of CSR1 expression is a novel mechanism critical for the oncogenic activity of miR-650. (Am J Pathol 2015, 185: 1991-1999; http://dx.doi.org/10.1016/j.ajpath.2015.03.015)
\end{abstract}

miRNAs are some well-conserved small noncoding RNA molecules of 20 to 22 bases in plants and mammals, playing a critical role in epigenetic regulation of gene expression. ${ }^{1} \mathrm{miR}-$ NAs silence targeted mRNA through base-pairing with the complementary sequences within the $3^{\prime}$ untranslated regions (UTRs) of mRNA molecules and block the ribosome complexes from translating the mRNAs into proteins. ${ }^{2}$ Approximately 1000 miRNAs are present in the human genome and are projected to target up to $60 \%$ of mRNA species. ${ }^{3,4}$ The differential expression of miRNA in different types of tissues may lead to differentiation of cells and tissues that form the organ system of the human body. Different sets of expressed miRNAs are found in different cell types and tissues.

Aberrant expression of miRNA is implicated in numerous human diseases. Abnormal expressions of a family of miRNAs targeted at DNA repairing pathways were implicated as potential causes of colon cancer and glioblastoma multiformis. ${ }^{6,7}$ Abnormal expression of miR-650 was previously shown to be associated with melanoma, ${ }^{8}$ gastric cancer, ${ }^{9}$ non-small cell lung cancer, ${ }^{10}$ chronic lymphocytic leukemia, ${ }^{11}$ and hepatocellular carcinoma. ${ }^{12}$ High level of miR-650 was shown to be a prognosticator for lymph node involvement and more aggressive clinical outcomes of lung adenocarcinoma. However, the mechanism of miR-650induced tumorigenesis remains unclear. Here, we showed that miR-650 was significantly up-regulated in prostate cancer (PC). High expression level of miR-650 was significantly associated with lower prostate-specific antigen-free survival rate. Expression of miR-650 inversely correlated with that of cellular stress response $1(C S R l)$, a tumor suppressor gene that is frequently down-regulated in PC. The oncogenic activity of miR-650 in PC is mediated by inhibition of CSR1 expression.

\section{Materials and Methods}

\section{Cells, Culture Conditions, and Antibodies}

All cell lines, including PC3 and DU145, were purchased from ATCC (Manassas, VA). PC3 cells were cultured with F12K medium supplemented with $10 \%$ fetal bovine serum

Supported by the National Cancer Institute grant RO1 CA098249 (J.-H.L.) and the American Cancer Society grant RSG-08-137-01-CNE (Y.P.Y.)

Disclosures: None declared. 
(Invitrogen, Carlsbad, CA). DU145 cells were cultured with modified Eagle medium supplemented with $10 \%$ fetal bovine serum (Invitrogen). These cell lines were purchased from ATCC in 2011. Authentication with short tandem repeat profiling was performed in 2013.

CSR1 antisera were raised in rabbits immunized with peptides that corresponded to CSR 1 coding sequence regions (AGLDLSLKDLTQECYDVKAAVHQINF). These antisera were peptide affinity-purified with the AminoLink kit from Pierce (Rockford, IL). The purified antisera were tested for binding specificity for CSR1 in a Western blot analysis with protein extracts from cells overexpressing CSR1 (PDC1 and PDC4) ${ }^{13}$ or cells not expressing CSR1 (PC3 and LNCaP cells). The antisera detected a single band of $72-\mathrm{kd}$ protein (the predicted molecular weight of CSR1).

\section{Human Cancer Patients and Specimens}

The PC specimens that were analyzed were archived as frozen or formalin-fixed, paraffin-embedded specimens of tissues from radical prostatectomies from 1985 through 2007. Specimens were selected largely on the basis of their availability or whether sufficient amounts of tumor tissues were present. The ages of patients at the time of surgery ranged from 45 through 79 years. For formalin-fixed, paraffin-embedded samples, 617 samples were collected, including 77 organ donor (OD) prostates from patients free of urologic diseases (obtained while patients were on heart-lung machine support), 324 benign prostate tissues adjacent to cancer, and 216 PCs. Two hundred fifteen of the 216 corresponding patients were followed clinically for at least 5 years. In addition, frozen tissues from 11 ODs, 20 benign prostate tissues adjacent to cancer, and $22 \mathrm{PC}$ samples were obtained for quantitative real-time RT-PCR (RT-qPCR). The protocols were approved by the University of Pittsburgh Institutional Review Board (Pittsburgh, PA).

Pure tumor specimens were obtained by dissecting freshly resected tissues, typically within 30 minutes of removal from patients. These tissues were frozen at $-80^{\circ} \mathrm{C}$ and were selected on the basis of tissue availability. Tissues were retrieved and microdissected immediately to $75 \%$ purity through microscopic needle dissection before the extraction of DNA or total RNA. Tumor cells were microdissected from frozen sections on slides by board-certified pathologists.

\section{Immunohistochemistry and Tissue Array Analysis}

For tissue microarray analysis, 671 formalin-fixed, paraffinembedded prostate tissue specimens were arrayed onto six slides, with one or two samples from each specimen. ${ }^{14}$ Patients in this group ranged in age from 45 to 79 years, and complete 5-year follow-up data were available for 215 patients with PC (University of Pittsburgh Medical Center tissue collection archive, 1985 through 2000). Immunohistochemistry was performed as described previously ${ }^{15}$ with purified CSR1 peptide antiserum (dilution 1:1000). Antigen retrieval was performed with $25 \mathrm{mmol} / \mathrm{L}$ sodium citrate buffer ( $\mathrm{pH}$ 9.0) at $90^{\circ} \mathrm{C}$ for 15 minutes, followed by treatment of $3 \% \mathrm{H}_{2} \mathrm{O}_{2}$ to block endogenous peroxidase. The slides were incubated at room temperature for 2 hours with anti-CSR1 antibodies at a 1:400 dilution. The sections were then incubated with horseradish peroxidase-conjugated anti-rabbit IgG for 30 minutes at room temperature. For visualization, horseradish peroxidase was reacted with 3,3'-diaminobenzidine solution (Dako, Carpinteria, CA). Cells were counterstained with hematoxylin. Immunohistochemistry specificity was verified by incubating similar slides with preimmune sera. The results of immunostaining were graded by three independent observers as 0 to 3 on the basis of intensity, with 0 being negative, 0.5 being focal positive, 1 being weakly positive, 2 being moderately positive, and 3 being strong positive. Each score represents the average value of five high-power fields.

\section{In Situ Hybridization}

The procedure of in situ hybridization was previously described. ${ }^{16}$ Briefly, formalin-fixed, paraffin-embedded tissue slides were treated with xylene for 16 hours, followed by washing in phosphate-buffered saline at room temperature three times. The tissues were then treated with proteinase $\mathrm{K}$ at $37^{\circ} \mathrm{C}$ for 15 minutes and washed with phosphate-buffered saline. The slides were quenched with $0.1 \% \mathrm{H}_{2} \mathrm{O}_{2}$ for 20 minutes and washed with phosphate-buffered saline. Hybridization was performed with a cocktail of biotin-cytosin- and bio-guanine-labeled oligonucleotides (5'-RGRURCRCRURGRARGRARGRCRGRCRURGRCRCRURCRCRU-3') in $6 \times$ standard saline citrate complementary to miR-650 sequence, which was added to the slides for 16 hours at $37^{\circ} \mathrm{C}$. The nonhybridized probes were removed by washing the tissues sequentially with $4 \times$ standard saline citrate, $2 \times$ standard saline citrate, and $0.2 \times$ standard saline citrate. The signals of hybridization were then amplified with one cycle of streptoavidin and biotinylated anti-streptoavidin treatment (ABC kit; Vector Laboratories, Burlingame, CA). The results of in situ hybridization were then visualized with diaminobenzidin treatment of the slides. The negative controls received a scramble biotin-labeled oligo probe $\left(5^{\prime}\right.$-TCCTGCGAGGCTGGTGGCTCCTGC-3'). The results of in situ hybridization were graded by three independent observers as 0 to 3 on the basis of intensity, with 0 being negative, 0.5 being focal positive, 1 being weakly positive, 2 being moderately positive, and 3 being strong positive. Each score represents the average value of five high-power fields.

\section{Immunoblot Analysis of CSR1 and Glyceraldehyde-3-} Phosphate Dehydrogenase

CSR1 expression in PC3 or DU145 cells transformed with pSingle-tTs-InhniR650 or pSingle-tTs-mimic miRNA650 was examined. First, cells were washed with phosphate-buffered saline and lyzed by RIPA buffer $(50 \mathrm{mmol} / \mathrm{L}$ Tris- $\mathrm{HCl}$ at $\mathrm{pH} 7.4$, $1 \%$ Nonidet P-40, $0.25 \%$ sodium deoxycholate, $150 \mathrm{mmol} / \mathrm{L}$ $\mathrm{NaCl}, 1 \mathrm{mmol} / \mathrm{L}$ EDTA, $1 \mathrm{mmol} / \mathrm{L}$ phenylmethylsulfonyl 

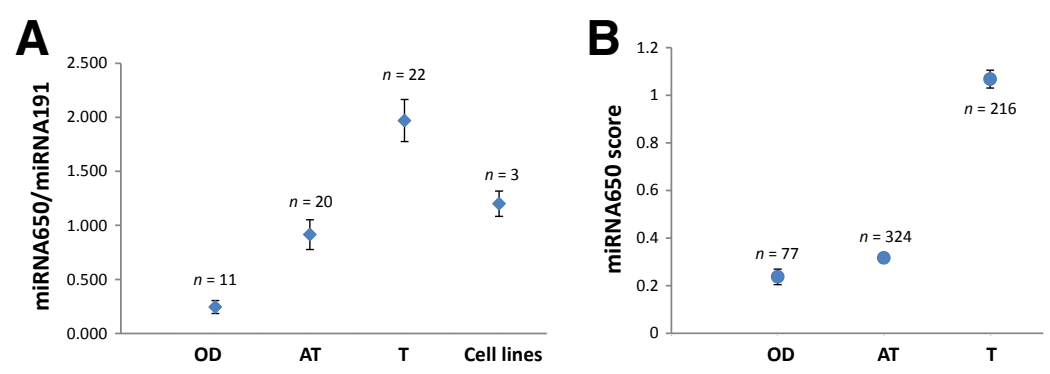

C

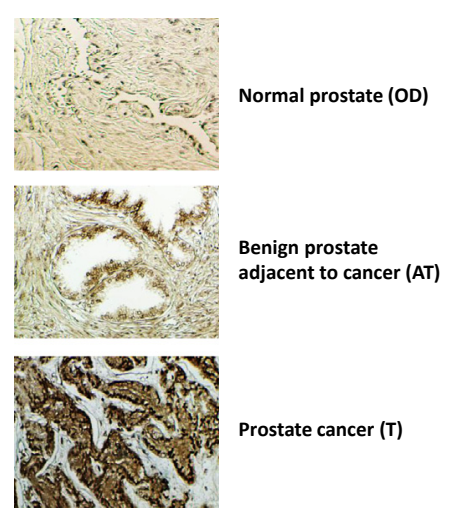

D

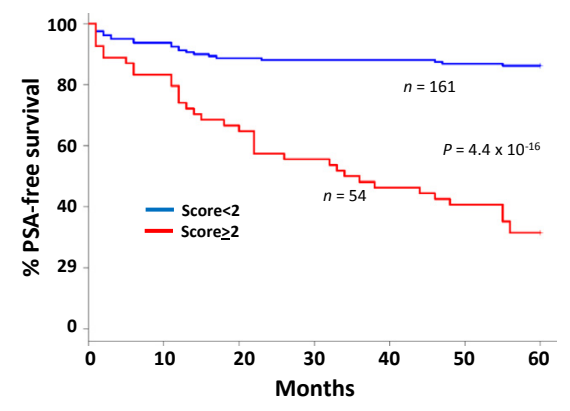

Figure 1 Expression of miR-650 is up regulated in prostate cancer. A: RT-qPCR of miR650 and control miR-191 of OD prostate, T, AT, and prostate cancer cell lines (PC3, DU145, and LNCaP). The numbers of samples for each type of tissues are indicated. B: In situ hybridization to detect the expression of miR-650 in 0D, AT, and T tissues. The numbers of samples for each type of tissues are indicated. C: Representative images of miR-650 in situ hybridization of miR-650 on 0D, AT, and T samples. D: Kaplan-Meier analysis of $T$ samples. The $T$ samples were segregated by miR650 expression scores of $<2$ or at least 2. Two hundred fifteen $T$ samples with at least 5 years clinical follow-up after radical prostatectomy were included in the analysis. AT, benign prostate tissue adjacent to cancer; OD, organ donor; PSA, prostate-specific antigen; RT-qPCR, quantitative real-time RT-PCR; T, prostate cancer. fluoride, aprotinin at $1 \mu \mathrm{g} / \mathrm{mL}$, leupeptin at $1 \mu \mathrm{g} / \mathrm{mL}$, pepstatin at $1 \mu \mathrm{g} / \mathrm{mL}$, and $1 \mathrm{mmol} / \mathrm{L} \mathrm{Na}_{3} \mathrm{VO}_{4}$ ). The lysates were sonicated and centrifuged at $12,000 \times g$ at $4{ }^{\circ} \mathrm{C}$ for 30 minutes to remove the insoluble materials. The proteins were separated by SDSPAGE in $8.5 \%$ polyacrylamide gels and were transferred onto a polyvinylidene difluoride membrane. The membrane was blocked with 5\% powdered skim milk in Tris-Tween 20 buffer $(0.1 \mathrm{~mol} / \mathrm{L}$ Tris- $\mathrm{HCl}$ and $0.1 \%$ Tween $20, \mathrm{pH} 7.4)$ for 1 hour at room temperature, followed by a 2-hour incubation with primary anti-CSR1 antibodies (dilution 1:1000) or antiglyceraldehyde-3-phosphate dehydrogenase antibodies (dilution 1:500; Abcam Inc., Cambridge, MA). The membrane was then washed three times with Tris-Tween 20 buffer and incubated with a horseradish peroxidase-conjugated secondary antibody specific for rabbit (anti-CSR1; dilution 1:1000) or goat (anti-glyceraldehyde-3-phosphate dehydrogenase; dilution 1:1000) for 1 hour at room temperature. The protein expression was detected with the electrochemiluminescence system (Amersham Life Science, Piscataway, NJ) according to the manufacturer's protocols.

\section{Colony Formation}

Colony formation assays were similar to those previously described. ${ }^{15,17-22}$ PIN 6 and DIN 8 cells were used. For colony formation assay, 5000 cells were cultured in 60-mm dishes. Triplicate experiments were performed for each cell clones. Medium was changed every 4 days. On the 10th day, the plates were stained with $1 \%$ crystal violet, and colonies with a diameter $>2 \mathrm{~mm}$ were counted.

To construct the vector that expresses inhibitor and mimics of miR-650 sequence, the following oligonucleotides were used: 5'-TCGAGGTCCTGAGAGCGCTGCCTCCTTTTT-
TTACGCGT- $3^{\prime}$ and $5^{\prime}$-AGCTTACGCGTAAAAAAAGGAGGCAGCGCtCtCAGGACC- $3^{\prime}$ for inhibitor of miR-650, $5^{\prime}$ TCGAGGTCCTGAGAGCGCTGCCTCCTTTTTTTACGCGT- $3^{\prime}$ and $5^{\prime}$-AGCTTACGCGTAAAAAAAGGAGGCAGCGCTCTCAGGACC- $3^{\prime}$ for mimics of miR-650. These primers were annealed and ligated into a pSingle-tTs-shRNA vector. The ligated products were transfected into Escherichia coli and plated on kanamycin plates $(50 \mu \mathrm{g} / \mathrm{mL})$. Fifteen colonies per transfection were picked and sequenced for the presence of inserts. The selected clones, which suppressed the expression of miR-650, were then transfected into PC3 and DU145 cells to generate cells that are doxycycline inducible for the suppression of miR-650. Induction of inhibitor of miR-650 was verified by RT-qPCR of cells induced with 5 $\mu \mathrm{g} / \mathrm{mL}$ doxycycline with the use of the following primers: 5'-GTCGTATCCAGTGCAGGGTCCGAGGTATTCGCACTGGATACGACAGGAGG-3' and 5'-CGGCGTCCTGAGAGCGCTG- $3^{\prime}$. To generate pLuc-CSR1, PCR was performed with primers $5^{\prime}$-CGGAAGACAGACGAGGAGAC- $3^{\prime}$ and 5'-GTCATCCAGGAAGGACGAGA-3' on CSR1 cDNA template under the following conditions: $94^{\circ} \mathrm{C}$ for 5 minutes then 30 cycles of $94^{\circ} \mathrm{C}$ for 30 seconds, $63^{\circ} \mathrm{C}$ for 1 minute, and $72^{\circ} \mathrm{C}$ for 4 minutes. This was followed by extension at $72^{\circ} \mathrm{C}$ for 10 minutes.

For mutant pLuc-CSR1, separate PCRs were performed on CSR1 cDNA template with the use of primer sets 5'-GTTCTCTCTGCACAGCTTTTTCCCTTGCTCTCCCTG- $3^{\prime}$ and $5^{\prime}$-ATCATGTCTGCTCGAAGCGG-3' and 5'-GGACTGACCGGCAAGTTGGAC-3' and 5'-CAGGGAGAGCAAGGGAAAAAGCTGTGCAGAGAGAAC-3' Second PCR was then performed on purified combined PCR products from the first PCRs by using primers 5 -GGACTGACCGGCAAGTTGGAC- $3^{\prime}$ and $5^{\prime}$-ATCATGTCTGCTC- 
Table 1 Association of Gleason's Grade and miR-650 Expression Scores

\begin{tabular}{lcc}
\hline Gleason's grade & No. of samples & $\begin{array}{r}\text { miR-650 score } \\
\text { (means } \pm \text { SD) }\end{array}$ \\
\hline 5 & 2 & $0.75 \pm 0.18$ \\
6 & 85 & $1.15 \pm 0.07$ \\
7 & 58 & $0.96 \pm 0.08$ \\
8 & 41 & $1.3 \pm 0.09$ \\
9 & 21 & $1.25 \pm 0.17$ \\
10 & 9 & $1.38 \pm 0.27$ \\
Combined Gleason & & \\
$\quad 5-7$ & 145 & $1.07 \pm 0.05$ \\
$\quad 8-10$ & 71 & $1.29 \pm 0.08$ \\
\hline
\end{tabular}

GAAGCGG-3'. The PCR products were then ligated into pLuc vector. The transfection efficiency was examined by co-transfection of cyanine $55^{\prime}$ end-labeled scramble oligonucleotide sequence 5'-TAATGTATTGGAACGCATATT-3' .

\section{Tumor Growth and Spontaneous Metastasis}

Approximately $1 \times 10^{7}$ viable PIN 6 and DIN 8 cells, suspended in $0.2 \mathrm{~mL}$ of Hanks' balanced salt solution (Krackeler Scientific, Inc., Albany, NY), were subcutaneously implanted in the abdominal flanks of 32 severe combined immunodeficient mice to generate one tumor per mouse. Mice were observed daily, and their body weight, tumor size, and lymph node enlargement were recorded weekly. Tumor and lymph node sizes were measured on the diameter. After 6 weeks or when mice became moribund, whichever occurred first, the mice were sacrificed, and necropsies were performed. Serial sections of formalin-fixed, paraffin-embedded lung, brain, liver, kidney, vertebra, and lymph node specimens were collected, stained with hematoxylin and eosin, and examined microscopically. All animal procedures were approved by the University of Pittsburgh Institutional Animal Care and Use Committee.

\section{Statistical Analysis}

Standard errors for individual proportions were calculated by use of the exact binomial test, and those for a numerical distribution were calculated with the following conventional independent and normal assumption: means $\pm(1.96 \times \mathrm{SD} /$ $n^{1 / 2}$ ), where $n=$ sample size. ${ }^{23}$ Comparison of two proportions was inferred by Fisher's exact test because of the relatively small sample sizes (function fisher.test in $\mathrm{R}$ package). ${ }^{23}$ Survival was analyzed by the Kaplan-Meier method, and survival curves were compared by use of the log-rank test. ${ }^{24}$ All statistical tests were two-sided.

\section{Results}

miR-650 Is Up-Regulated and Inversely Correlated with CSR1 Expression in Prostate Cancer Samples

The mechanisms that govern the expression of CSR1 remain unclear. To investigate the potential mechanism of CSR1 expression regulation, the $3^{\prime}$ UTR of CSR 1 was analyzed for miRNA targeting by using miRWalk version 2.0 ( $h t t p: / /$ www.umm.uni-heidelberg.delapps/zmf/mirwalk, last accessed March 5, 2015). A total of 20 potential miRNA target sites and 16 unique miRNAs were identified targeting at the $3^{\prime}$ UTR of CSR1. Among these miRNAs, five are known to be oncogenic (miR-297, -484, -1182, -210, and -650). To investigate the relevance of these oncogenic miRNAs in PC, RT-qPCRs with primers corresponding to these miRNAs were performed on PC cell lines PC3, DU145, and LNCaP and 11 fresh-frozen OD prostate samples. Only miR-650 was shown to be up-regulated in PC cell lines (Figure 1A). As a
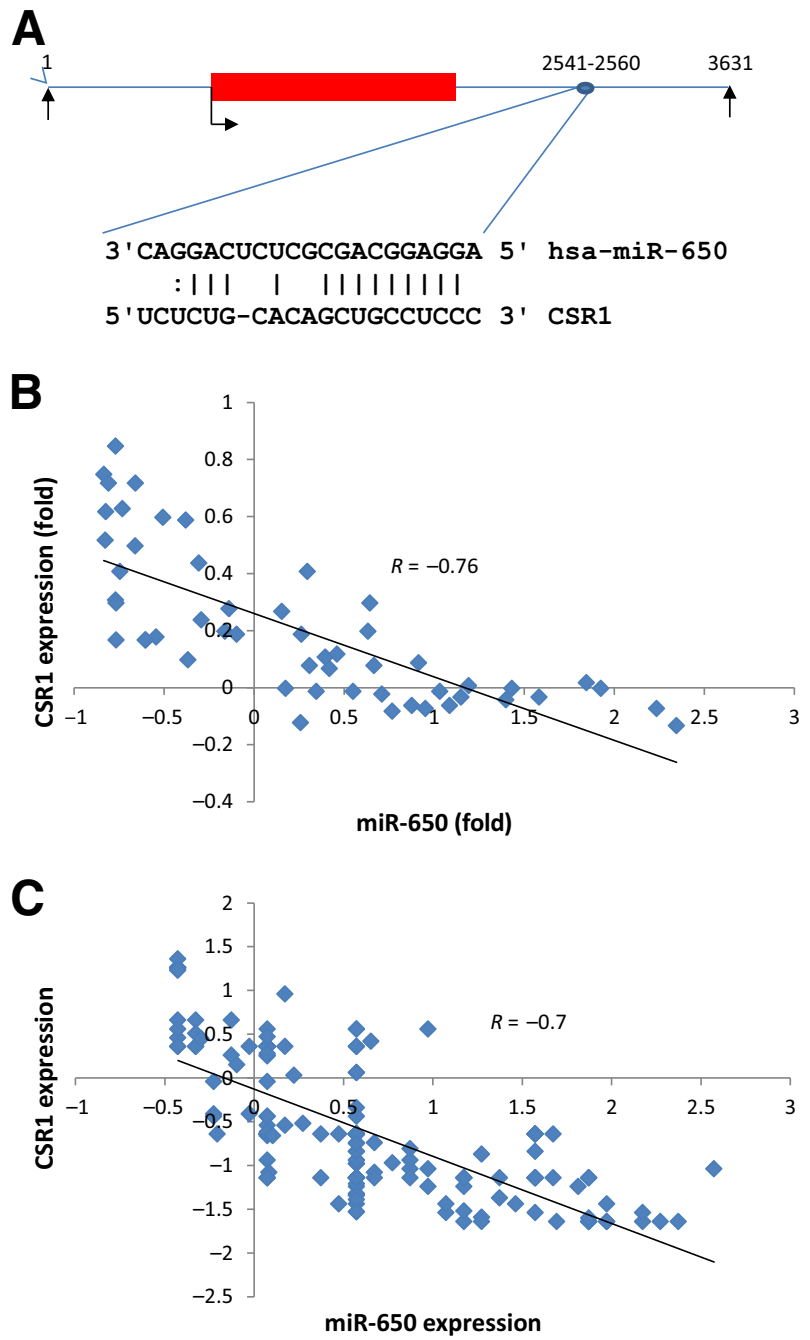

Figure 2 CSR1 expression inversely correlates with the expression of miR-650. A: Schematic diagram of CSR1 transcript and mapping homology between hsa-miR-650 and CSR1 $3^{\prime}$ UTR. Coding RNA sequence is indicated by red box. $5^{\prime}$ and $3^{\prime}$ UTRs are indicated by blue lines. The number of nucleotides is indicated for the position of miR-650 binding site. B: Correlation of miR-650 expression with that of CSR1 in 53 prostate samples with the use of RT-qPCR. Pearson correlation coefficient value is indicated. C: Correlation of miR-650 expression with that of CSR1 in 166 prostate samples with the use of in situ hybridization (miR-650) and immunostaining (CSR1). Pearson correlation coefficient value is indicated. RT-qPCR, quantitative real-time RT-PCR; UTR, untranslated region. 


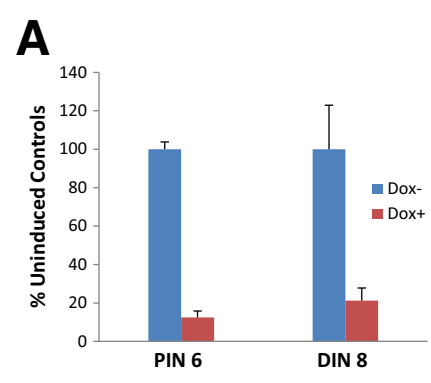

D

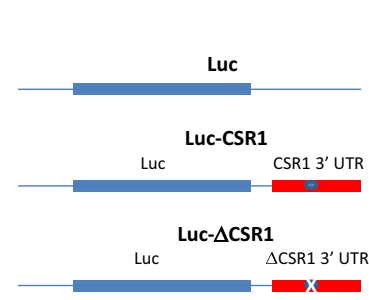

B

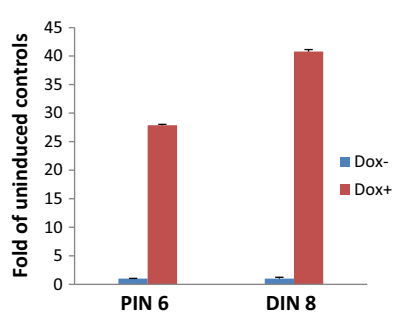

E

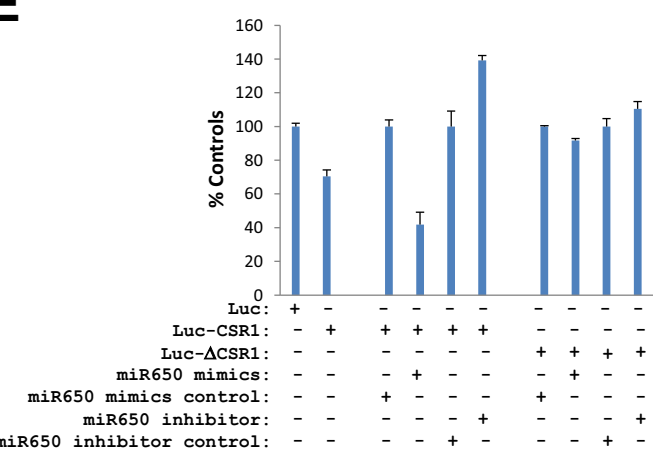

Figure 3 miR-650 targeting at CSR $13^{\prime}$ UTR site. A-C: Inhibitor of miR-650 enhances the expression of CSR1. PC3 (PIN 6) or DU145 (DIN 8) cells transformed with pSingle-inhmiR650 were induced with Dox. The expressions of miR-650 and CSR1 were quantified. A: RT-qPCR of miR-650/miR191; B: qRT-PCR of CSR1 mRNA; C: immunoblotting of CSR1 and GAPDH. D: miR-650 target site in the $3^{\prime}$ UTR of CSR1. Diagram of reporter gene luciferase under the control of $P G K$ promoter, reporter gene with $3^{\prime}$ UTR of CSR1, and reporter gene with $3^{\prime}$ UTR of $\triangle$ CSR1 that contains four nucleotide mutations at the target site of miR-650. E: Luciferase assays on PC3 cells transformed with indicated vectors and controls. DOX, doxycycline; GAPDH, glyceraldehyde-3-phosphate dehydrogenase; Luc, luciferase; RT-qPCR, quantitative realtime RT-PCR; UTR, untranslated region. result, miR-650 was selected for further analyses. miR-650 was implicated in a number of human malignancies. ${ }^{8-12}$ To investigate the role of miR-650 in PC, RT-qPCR with primers specific for miR-650 was performed on 56 fresh-frozen prostate samples, including $22 \mathrm{PC}, 20$ benign prostate tissues adjacent to cancer (AT), 11 OD prostates, and three PC cell lines (PC3, DU145, and LNCaP). Our results show an average 2.2-fold increase of miR-650 in PC samples in comparison with benign prostate tissues adjacent to cancer, and more than eightfold increase over the OD prostates from patients free of urologic disease (Figure 1A).

To investigate the clinical correlation between the expression of miR-650 and PC, in situ hybridizations of miR-650 were performed on 617 formalin-fixed, paraffin-embedded prostate samples, including 216 PC, 77 OD prostates, and 324 benign prostate tissues adjacent to cancer. The signals of hybridization from each sample were classified on the basis of intensity as strong positive (score $=3$ ), moderate positive (score $=2$ ), weakly positive (score $=1$ ), focal (score $=0.5$ ), or negative $($ score $=0)$. The score from each sample represents the average of scores graded by three observers. Most of the PC samples were at least weakly positive for miR-650 (average score $=1.14$ ) (Figure 1B). In contrast, expressions of miR-650 were mostly focal in both OD (average score $=0.23$ ) and benign prostate tissue adjacent to cancer (average score $=0.32$ ) (Figure 1, B and C). This represents a 3.6-fold increase of miR650 expression in PC cells in comparison with benign prostate tissues adjacent to cancer $\left(P=4.9 \times 10^{-48}\right)$ and a 4.9 -fold in comparison with $\mathrm{OD}$ prostates $\left(P=1.3 \times 10^{-43}\right)$. The expression of miR-650 is significantly associated with higher ( 8 to 10 versus 5 to 7$)$ Gleason's grade $(P=0.012)$ (Table 1$)$. When PC samples were segregated on the basis of miR-650 score cutoff at 2, patients with miR-650 expression scores of at least 2 experienced significantly lower rate of prostatespecific antigen-free survival $(31 \%)$ in comparison with patients with score $<2\left(86 \% ; P=4.4 \times 10^{-16}\right)$ (Figure 1D). These results suggest that expression of miR-650 correlates with the aggressiveness of $\mathrm{PC}$ and is indicative of a poor clinical outcome.

Previous works had shown a significant down-regulation of CSR1 in PC and glioblastoma multiformis. ${ }^{13}$ Expression of CSR1 inhibited PC growth and induced cell death. Thirteen bases of miR-650 appear to complement to a sequence in $3^{\prime}$ UTR in CSR1 (c.2996-3015 of NM_016240.2) (Figure 2A). We hypothesize that high level of expression of miR-650 correlates with low level of expression of CSR1. To examine whether there is an inverse correlation between miR-650 and CSR1 expression, 53 fresh-frozen prostate samples that were examined for miR-650 were evaluated for CSR 1 expression with RT-qPCR. The results showed a trend of inverse correlation between CSR 1 and miR-650 expressions (Pearson correlation coefficient $=-0.76)$ (Figure $2 \mathrm{~B})$. To validate this correlation, a correlation analysis was performed on a separate cohort of 166 formalin-fixed, paraffin-embedded samples of PC and benign prostate tissues with immunohistochemistry staining of CSR 1 expression and in situ hybridization of miR-650. The correlation yielded a similar inverse correlation of miR-650 and CSR1 expression (Pearson correlation coefficient $=-0.7$ ) (Figure 2C). These results support an inverse relation between CSR1 and miR-650 expression.

\section{miR-650 Down-Regulates CSR1 Expression through 3' UTR of CSR1}

To examine whether the putative miR-650 target site in the $3^{\prime}$ UTR of CSR1 is functional, an inhibitor of miR-650 was 


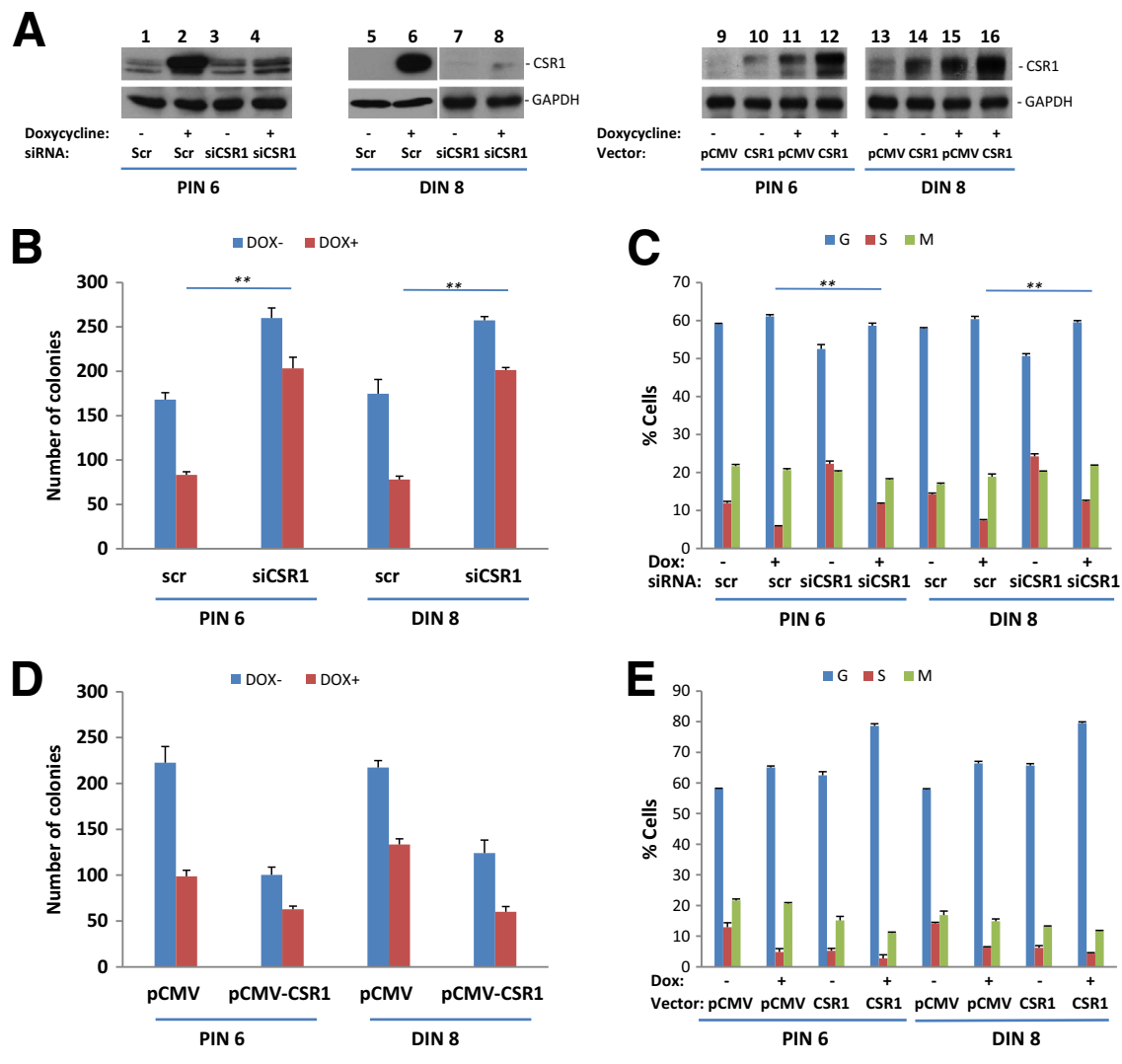

Figure 4 miR-650 promotes cancer cell growth through down-regulation of CSR1. A: Immunoblots of PIN 6 and DIN 8 cells treated with siCSR1 or scr or pCMV-CSR1 or pCMVscript. B: Inhibitor of miR-650 inhibits colony formation of prostate cancer cell lines through down-regulation of CSR1. PIN 6 and DIN 8 cells of $\mathbf{A}$ were transfected with the indicated siRNA and induced with or without doxycycline. Colony formation assays were performed. C: Inhibitor of miR-650 inhibits cell cycle entry to $S$ phase. BrdU labeling and cell cycle analyses were performed on cells from A. D: CSR1 exacerbates inhibition of colony formation induced by inhibitor of miR-650. Colony formation assays were performed on cells from A. E: CSR1 exacerbates inhibition of cell cycle entry to $S$ phase induced by inhibitor of miR-650. BrdU labeling and cell cycle analyses were performed on cells from $\mathbf{A}$. ${ }^{* *} P<0.01$. BrdU, bromodeoxyuridine; GAPDH, glyceraldehyde-3-phosphate dehydrogenase; $\mathrm{pCMV}$, phosphorylated cytomegalovirus; scr, scramble control; siCSR1, siRNA specific for CSR1.

constructed into pSingle-tTs-shRNA vector to generate pSingle-inhmiR-650. This vector was then transfected into PC3 and DU145 cells. Fifteen colonies from each lineage were selected. Two clones (PIN 6 from PC3 cells transformed with pSingle-inhmiR-650 and DIN 8 from DU145 cells transformed with pSingle-inhmiR-650) were selected for characterization. Our analyses showed that induction of PIN 6 and DIN 8 with doxycycline $(5 \mu \mathrm{g} / \mathrm{mL})$ reduced the expression of miR-650 by 8.2- and 4.8-fold in PIN 6 and DIN 8 cells, respectively (Figure 3A). The decrease of miR-650 expression was accompanied with 27- and 40-fold increase of CSR1 mRNA in these cells (Figure 3B). The increase of CSR 1 mRNA resulted in dramatically higher level of CSR1 in these cells (Figure 3C).

To investigate whether the putative miR-650 target site in the $3^{\prime}$ UTR of CSR 1 is functional in a different context, the $3^{\prime}$ UTR sequence (1650 bp) of CSR1 was ligated into the $3^{\prime}$ end of luciferase reporter gene that is driven by phosphoglycerate kinase 1 promoter to generate pLucCSR1 (Figure 3D). Co-transfection of pLuc-CSR1 and pSingle-mimiR-650, a mimic of miR-650, reduced the reporter gene activity by $60 \%(P<0.001)$ in comparison with the controls (Figure 3E). In contrast, when pLucCSR1 was co-transfected with pSingle-inhmiR-650, the reporter gene activity increased by $40 \%(P<0.001)$.

To investigate whether the putative target site is critical for miR-650 activity, a four-nucleotide point mutation was introduced to the miR-650 binding site in the $3^{\prime}$ UTR of
CSR1 sequence. The mutation completely abrogated the activity of miR-650 (Figure 3E). These results indicate that the miR-650 target sequence in $3^{\prime}$ UTR is the crucial binding site for miR-650 and mediates its CSR1 downregulation activity.

\section{Oncogenic Activity of miR-650 Is Mediated by CSR1 in Vitro and in Vivo}

CSR1 contains tumor suppressor activity. High level expression of miR-650 in PC cell lines suppresses CSR1 expression. Because down-regulation of CSR1 induces carcinogenesis, we hypothesize that miR-650 contains oncogenic activity because of its negative impact on CSR1 expression. When PIN 6 and DIN 8 cells were induced to express the inhibitor of miR-650, expression of CSR1 was recovered in both cell lines (Figure 4, $\mathrm{A}$ and $\mathrm{B}$ ). The higher levels of CSR1 were accompanied with $>50 \%$ to $55 \%$ drops in colony formation in PIN 6 and DIN 8 cells. Cell cycle analyses indicate that expression of inhibitor of miR-650 reduced cell cycle entry into S phase for PIN 6 and DIN 8 cells by 2.1- and 2.2-fold, respectively, suggesting that miR-650 induces cell growth in these cell lines. To investigate whether CSR 1 is the main mediator for miR650-induced cell growth, PIN 6 and DIN 8 cells were treated with siRNA specific for CSR1. These cells were then induced with doxycycline to express inhibitor of miR-650 to reduce the expression of miR-650. Knocking down of CSR1 significantly reversed the antiproliferation activity of inhibitor of miR- 650 

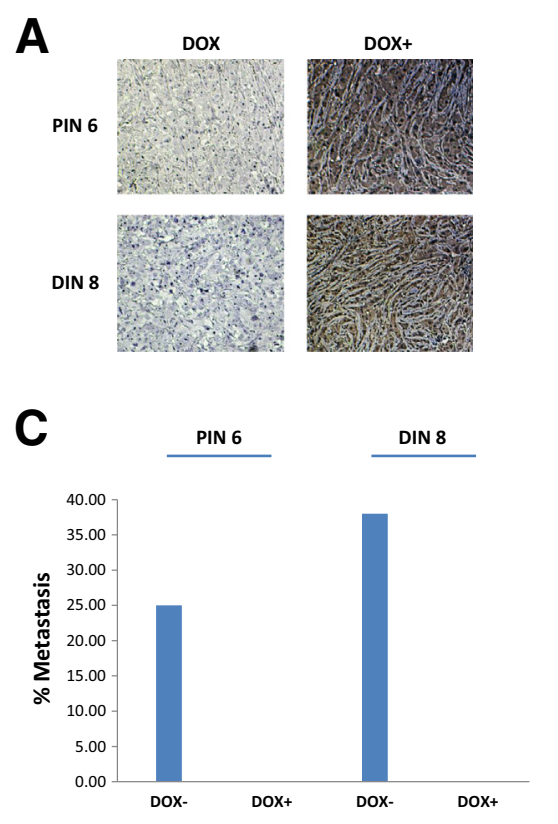

B

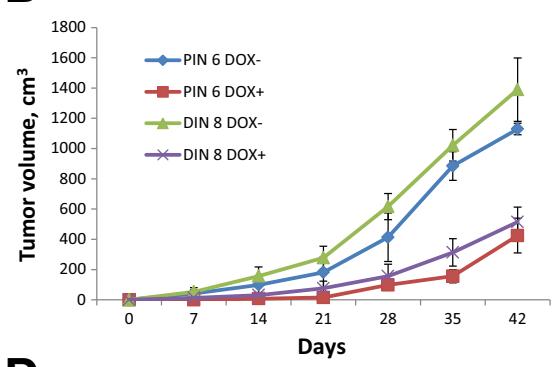

D

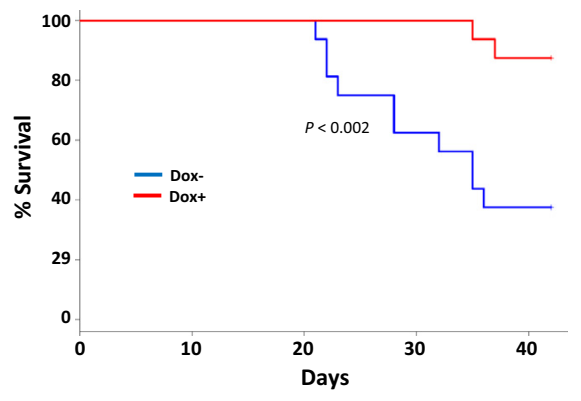

Figure 5 Inhibitor of miR-650 decreases tumor volume, metastasis, and mortality of prostate cancer cells. A: Representative image of immunostaining of CSR1 in xenografted PIN 6 and DIN 8 tumors in SCID mice. The mice were fed with or without $5 \mu \mathrm{g} / \mathrm{mL}$ DOX water. B: Growth curves of PIN 6 and DIN 8 cells xenografted into subcutaneous regions of SCID mice treated with or without $5 \mu \mathrm{g} / \mathrm{mL}$ DOX water. C: Rate of metastasis of xenografted PIN 6 and DIN 8 tumors in mice treated with or without $5 \mu \mathrm{g} / \mathrm{mL}$ DOX water. D: Kaplan-Meier analysis of PIN 6 and DIN 8 tumors in SCID mice within 42 days after xenografting, treated with or without $5 \mu \mathrm{g} / \mathrm{mL}$ DOX water. $n=$ 16 PIN 6 tumors; $n=16$ DIN 8 tumors. DOX, doxycycline; SCID, severe combined immunodeficient.
$(P<0.01)$ (Figure 4, A-C). When PIN 6 and DIN 8 cells were transfected with recombinant plasmid pCMV-CSR1, it exacerbated the colony formation inhibition induced by the inhibitor of miR-650 and induced cell growth arrest when these cells were induced with doxycycline. These results suggest that down-regulation of CSR1 is one of the important mechanisms of miR-650-induced cell growth and DNA replication (Figure 4, D and E).

To investigate the oncogenic impact of miR-650 on PC cells, PIN 6 and DIN 8 cells were xenografted subcutaneously onto severe combined immune deficient mice. Mice treated with doxycycline to induce the expression of inhibitor of miR-650 had significantly smaller tumor volume $\left(1.26 \mathrm{~cm}^{3}\right.$ versus $\left.0.47 \mathrm{~cm}^{3} ; P<0.001\right)$ (Figure 5). Thirtyone percent (5 of 16) of mice of the untreated control group experienced cancer metastasis or invasion into other organs such as lung, vertebra, or liver. In contrast, none of the mice treated with doxycycline experienced metastasis. Sixty-three percent (10 of 16) of mice in the untreated control group died within 42 days after the tumor cell inoculation, whereas only $13 \%$ ( 2 of 16 ) of mice treated with doxycycline experienced early death $(P=0.0018)$. These results suggest that miR650 contains oncogenic and cancer metastasis promotional activity because removal of miR-650 reduced tumor growth and metastasis of the cancer cells.

\section{Discussion}

The CSRI gene was originally identified as a cellular stress response protein. ${ }^{25}$ It is widely expressed in most tissues, and it functions to protect cells from the damaging effects of reactive oxygen intermediates. ${ }^{25}$ CSR 1 is located at $8 p 21$, a region that is frequently deleted in a variety of human malignancies, including PC. ${ }^{26,27}$ Previous studies indicated that down-regulation of CSR1 was identified in PC. ${ }^{13,16,28}$ Forced expression of CSR1 in PC cell lines suppressed cell growth and induced cell death. The tumor suppressor mechanism of CSR1 is mediated by inhibition of mRNA mature through redistribution and hijacking cleavage and polyadenylation-specific factor $3,{ }^{20}$ a critical factor for premRNA cleavage and polyadenylation. ${ }^{29,30}$ A recent study also suggests that CSR1 inhibits X-linked inhibitor of apoptosis activity and promotes cell death. ${ }^{17}$ The promoter region of CSR1 was found hypermethylated in a significant number of cancer samples. ${ }^{13}$ However, the decrease of CSR1 and level of methylation is not correlated. Significant number of PC samples had low level of CSR1 expression but were not methylated in its promoter region. ${ }^{13}$

To our knowledge, this is the first report to indicate that CSR1 expression is regulated by a miRNA. Several lines of evidence support that miR-650 interacts with its target site in the $3^{\prime}$ UTR of CSR1. First, consistent inverse correlation between CSR1 and miR-650 expression was observed in two independent cohorts. Second, removal of miR-650 from the cells through expression of the inhibitor of miR-650 dramatically reversed the expression of CSR 1 . Third, mutations at the putative target sites of miR-650 abrogated its CSR1 suppression activity in the reporter gene system. Taken together, our analysis indicates that miR-650 plays a crucial role in regulating the expression of CSR1. Our previous analyses showed that $>90 \%$ of PCs retained the genome sequence that contained the CSRI gene. ${ }^{13}$ However, it is possible that some of these cancers have homozygous deletions of CSRI because CSRI is located in the region where genomic deletions are frequent among PC samples. The present finding supports that miR-650 might 
play a significant role in shutting down the expression of CSRl from the remaining allele and thus exacerbates the aggressive behavior of PC.

The oncogenic role of miR-650 was implicated in several human malignancies. However, conflicting mechanisms were suggested. Our animal study and in vitro analysis clearly indicate that miR-650 is oncogenic. The oncogenic activity of miR-650 is mediated by its down-regulation of CSR1 in cancer cells. Up-regulation of miR-650 is widespread among PC samples. High level of miR-650 is also associated with poor differentiation of the cancer and higher rate of PC recurrence. These results mirror those of CSR1. Because inhibitor of miR-650 dramatically elevated the expression of CSR1 and significantly reduced tumor volume, metastasis, and rate of mortality in our animal model, it provides a possible means to treat aggressive PC through tissue-specific expression of this inhibitor.

The mechanism of up-regulation of miR-650 in PC remains unclear. Some studies suggested that miR-650 expression was induced by p16(INK4a) because $p 16^{-1-}$ cell lines have low level of miR- $650 .^{31}$ miR-650 is located in the long arm of chromosome 22 (22q11.22). It is sandwiched between the exons of immunoglobulin light chain constant region. Rearrangement and hypermutations of $\lambda$ light chain occur in B-cell maturation. Thus, this region is probably a part of an unstable region in the chromosome. Genome instability was associated with aggressive PC because higher levels of copy number variance, ${ }^{26}$ chromosome rearrangement, ${ }^{32}$ and fusion transcript formation ${ }^{33}$ are found in PC that proves metastatic and lethal. Alternatively, abnormalities of cancer genome methylation may be responsible for the high level expression of miR650 because significant alterations of methylation patterns were found in PC samples. ${ }^{34-36}$ Future investigation into the miR-650 expression regulation should shed light on the mechanism of miR-650 expression abnormalities and the aggressive behavior of PC.

\section{Acknowledgments}

We thank George Michalopoulos and Joel Nelson for their constructive comments on the manuscript.

\section{References}

1. Chen K, Rajewsky N: The evolution of gene regulation by transcription factors and microRNAs. Nat Rev Genet 2007, 8: 93-103

2. Bartel DP: MicroRNAs: target recognition and regulatory functions. Cell 2009, 136:215-233

3. Bentwich I, Avniel A, Karov Y, Aharonov R, Gilad S, Barad O, Barzilai A, Einat P, Einav U, Meiri E, Sharon E, Spector Y, Bentwich Z: Identification of hundreds of conserved and nonconserved human microRNAs. Nat Genet 2005, 37:766-770

4. Lewis BP, Burge CB, Bartel DP: Conserved seed pairing, often flanked by adenosines, indicates that thousands of human genes are microRNA targets. Cell 2005, 120:15-20
5. Lagos-Quintana M, Rauhut R, Yalcin A, Meyer J, Lendeckel W, Tuschl T: Identification of tissue-specific microRNAs from mouse. Curr Biol 2002, 12:735-739

6. Tessitore A, Cicciarelli G, Del Vecchio F, Gaggiano A, Verzella D, Fischietti M, Vecchiotti D, Capece D, Zazzeroni F, Alesse E: MicroRNAs in the DNA damage/repair network and cancer. Int J Genomics 2014 2014:820248

7. Zhang W, Zhang J, Hoadley K, Kushwaha D, Ramakrishnan V, Li S, Kang C, You Y, Jiang C, Song SW, Jiang T, Chen CC: miR-181d: a predictive glioblastoma biomarker that downregulates MGMT expression. Neuro Oncol 2012, 14:712-719

8. Chan E, Patel R, Nallur S, Ratner E, Bacchiocchi A, Hoyt K, Szpakowski S, Godshalk S, Ariyan S, Sznol M, Halaban R, Krauthammer M, Tuck D, Slack FJ, Weidhaas JB: MicroRNA signatures differentiate melanoma subtypes. Cell Cycle 2011, 10:1845-1852

9. Zhang X, Zhu W, Zhang J, Huo S, Zhou L, Gu Z, Zhang M: MicroRNA-650 targets ING4 to promote gastric cancer tumorigenicity. Biochem Biophys Res Commun 2010, 395:275-280

10. Huang JY, Cui SY, Chen YT, Song HZ, Huang GC, Feng B, Sun M, De W, Wang R, Chen LB: MicroRNA-650 was a prognostic factor in human lung adenocarcinoma and confers the docetaxel chemoresistance of lung adenocarcinoma cells via regulating Bcl-2/Bax expression. PLoS One 2013, 8:e72615

11. Mraz M, Dolezalova D, Plevova K, Stano Kozubik K, Mayerova V, Cerna K, Musilova K, Tichy B, Pavlova S, Borsky M, Verner J, Doubek M, Brychtova Y, Trbusek M, Hampl A, Mayer J, Pospisilova S: MicroRNA-650 expression is influenced by immunoglobulin gene rearrangement and affects the biology of chronic lymphocytic leukemia. Blood 2012, 119:2110-2113

12. Zeng ZL, Li FJ, Gao F, Sun DS, Yao L: Upregulation of miR-650 is correlated with down-regulation of ING4 and progression of hepatocellular carcinoma. J Surg Oncol 2013, 107:105-110

13. Yu G, Tseng GC, Yu YP, Gavel T, Nelson J, Wells A, Michalopoulos G, Kokkinakis D, Luo JH: CSR1 suppresses tumor growth and metastasis of prostate cancer. Am J Pathol 2006, 168:597-607

14. Ren B, Yu G, Tseng GC, Cieply K, Gavel T, Nelson J, Michalopoulos G, Yu YP, Luo JH: MCM7 amplification and overexpression are associated with prostate cancer progression. Oncogene 2006, 25:1090-1098

15. Jing L, Liu L, Yu YP, Dhir R, Acquafondada M, Landsittel D, Cieply K, Wells A, Luo JH: Expression of myopodin induces suppression of tumor growth and metastasis. Am J Pathol 2004, 164:1799-1806

16. Luo JH, Yu YP, Cieply K, Lin F, Deflavia P, Dhir R, Finkelstein S, Michalopoulos G, Becich M: Gene expression analysis of prostate cancers. Mol Carcinog 2002, 33:25-35

17. Zheng ZL, Tan LZ, Yu YP, Michalopoulos G, Luo JH: Interaction of CSR1 with XIAP reverses inhibition of caspases and accelerates cell death. Am J Pathol 2012, 181:463-471

18. Wang H, Luo K, Tan LZ, Ren BG, Gu LQ, Michalopoulos G, Luo JH, Yu YP: p53-induced gene 3 mediates cell death induced by glutathione peroxidase 3. J Biol Chem 2012, 287:16890-16902

19. Han YC, Yu YP, Nelson J, Wu C, Wang H, Michalopoulos GK, Luo JH: Interaction of integrin-linked kinase and miniature chromosome maintenance 7-mediating integrin \{alpha\}7 induced cell growth suppression. Cancer Res 2010, 70:4375-4384

20. Zhu ZH, Yu YP, Shi YK, Nelson JB, Luo JH: CSR1 induces cell death through inactivation of CPSF3. Oncogene 2009, 28:41-51

21. Yu YP, Yu G, Tseng G, Cieply K, Nelson J, Defrances M, Zarnegar R, Michalopoulos G, Luo JH: Glutathione peroxidase 3, deleted or methylated in prostate cancer, suppresses prostate cancer growth and metastasis. Cancer Res 2007, 67:8043-8050

22. Ren B, Yu YP, Tseng GC, Wu C, Chen K, Rao UN, Nelson J, Michalopoulos GK, Luo JH: Analysis of integrin alpha7 mutations in prostate cancer, liver cancer, glioblastoma multiforme, and leiomyosarcoma. J Natl Cancer Inst 2007, 99:868-880

23. Rice J (Ed): Mathematical Statistics and Data Analysis. Pacific Grove, CA, Duxbury Press, 2006 
24. Hosmer DW, Lemeshow S (Eds): Applied Survival Analysis. Hoboken, NJ, Wiley, 2003

25. Han HJ, Tokino T, Nakamura Y: CSR, a scavenger receptor-like protein with a protective role against cellular damage causedby UV irradiation and oxidative stress. Hum Mol Genet 1998, 7:1039-1046

26. Yu YP, Song C, Tseng G, Ren BG, Laframboise W, Michalopoulos G, Nelson J, Luo JH: Genome abnormalities precede prostate cancer and predict clinical relapse. Am J Pathol 2012, 180:2240-2248

27. Luo JH, Yu YP: Genetic factors underlying prostate cancer. Expert Rev Mol Med 2003, 5:1-26

28. Yu YP, Landsittel D, Jing L, Nelson J, Ren B, Liu L, McDonald C, Thomas R, Dhir R, Finkelstein S, Michalopoulos G, Becich M, Luo JH: Gene expression alterations in prostate cancer predicting tumor aggression and preceding development of malignancy. J Clin Oncol 2004, 22:2790-2799

29. Dominski Z, Yang XC, Marzluff WF: The polyadenylation factor CPSF-73 is involved in histone-pre-mRNA processing. Cell 2005, 123 : $37-48$

30. Ryan K, Calvo O, Manley JL: Evidence that polyadenylation factor CPSF-73 is the mRNA 3' processing endonuclease. RNA 2004, 10: $565-573$

31. Chien WW, Domenech C, Catallo R, Kaddar T, Magaud JP, Salles G, Ffrench M: Cyclin-dependent kinase 1 expression is inhibited by
p16(INK4a) at the post-transcriptional level through the microRNA pathway. Oncogene 2011, 30:1880-1891

32. Baca SC, Prandi D, Lawrence MS, Mosquera JM, Romanel A, Drier Y, et al: Punctuated evolution of prostate cancer genomes. Cell 2013, 153:666-677

33. Tomlins SA, Rhodes DR, Perner S, Dhanasekaran SM, Mehra R, Sun XW, Varambally S, Cao X, Tchinda J, Kuefer R, Lee C, Montie JE, Shah RB, Pienta KJ, Rubin MA, Chinnaiyan AM: Recurrent fusion of TMPRSS2 and ETS transcription factor genes in prostate cancer. Science 2005, 310:644-648

34. Yu YP, Ding Y, Chen R, Liao SG, Ren BG, Michalopoulos A, Michalopoulos G, Nelson J, Tseng GC, Luo JH: Whole-genome methylation sequencing reveals distinct impact of differential methylations on gene transcription in prostate cancer. Am J Pathol 2013, 183: 1960-1970

35. Luo JH, Ding Y, Chen R, Michalopoulos G, Nelson J, Tseng G, Yu YP: Genome-wide methylation analysis of prostate tissues reveals global methylation patterns of prostate cancer. Am J Pathol 2013, 182: 2028-2036

36. Yu YP, Paranjpe S, Nelson J, Finkelstein S, Ren B, Kokkinakis D, Michalopoulos G, Luo JH: High throughput screening of methylation status of genes in prostate cancer using an oligonucleotide methylation array. Carcinogenesis 2005, 26:471-479 